Recebido: $10 / 03 / 2014$

Aprovado: 31/12/2014

\title{
Primeira República: Espaço para a mulher no ensino técnico em Portugal
}

\author{
Luis Alberto Marques Alves*
}

Resumo: A mulher teve na la República portuguesa (1910-1926) um protagonismo social que obrigou os diferentes governos a incluir na esfera educativa um espaço especial para a sua formação. No ensino técnico houve a preocupação de criar cursos específicos para setores que vão desde as rendas à telegrafia, desde o comércio ao desenho, da olaria à pintura decorativa. A expectativa em formar profissionais para profissões novas, mas também renovar o seu espaço socioprofissional e contrariar a permanência no espaço doméstico, levou à criação de cursos, no ensino oficial e particular, destinados especificamente à mulher e que se revelaram ou um fracasso - por exemplo o de economia doméstica - ou um sucesso - caso das oficinas das escolas de desenho industrial. Há cursos especiais que são criados nas escolas industriais - por exemplo o de Lavores Femininos que têm logo grande adesão. No segmento temporal de 1914/1919, apesar de coincidir com a $1^{\text {a }}$ Guerra Mundial, verifica-se uma tendência que é também visível no período em estudo: a adesão feminina foi sempre maior nos trabalhos oficinais do que nas disciplinas que constituíam os cursos estruturados em formação mais geral e técnica. Das intenções expressas pelos políticos republicanos às realidades evidenciadas pela história da educação portuguesa daremos conta numa breve incursão pelas medidas implementadas e pela adesão feminina evidenciada.

Palavras-chave: Mulher; Ensino Técnico; Portugal.

\begin{abstract}
The woman had, in the $1^{\text {st }}$ Portuguese Republic (1910-1026), a social protagonism that obey the different governments to include in the educative sphere a special space for her education. In the technical education it was the concern of creat specific courses for sectores from rents to telegraphy, from trade to drawing, from pottery to decorative painting. The expectation of teach professionals for new professions, but also renew its social-professional space and counter the permanence in the domestic space, led to the creation of courses, in the official and private education, intended specifically to woman and that proved to be a failure - for example the one about domestic economy -
\end{abstract}

*Professor Associado com agregação do Departamento de História e Estudos Políticos Internacionais da Faculdade de Letras da Universidade do Porto, Portugal. Investigador do CITCEM - FLUPGVT, Salvador BA. 
or a success - the case of the workshops of the schools of industrial drawing. There are special courses that are created in the industrial schools - for example the one about Female Handcraft that has immediately a big accession. In the temporal segment of $1914 / 1919$, despite be coincident with the $1^{\text {st }}$ World War, we can see a trend that is also visible in the period of the study: the female accession was always bigger in the workshop jobs than in subjects of more structured courses of general and technical education. From the expressed intentions by the republican politicians to the evidenced realities by history of Portuguese education we will make a brif incursion by the implemented actions and by the evidenced female accession.

Keywords: Woman; Technical Education; Portugal. 


\section{Preâmbulo}

$\mathrm{Art}^{\circ} 1^{\circ}$-A oficina anexa à escola Marquês de Pombal, em Alcântara, tem por fim, em harmonia com o ensino de desenho e a ele subordinada como sua imediata aplicação:

$1^{\circ}$ Facilitar às alunas a execução de lavores femininos, representados nos desenhos por elas feitos na escola;

$2^{\circ}$ Dar-lhes a conhecer praticamente alguns processos, instrumentos e aparelhos, que muitas vezes não encontram nos estabelecimentos onde trabalham e promover o máximo rigor na exactidão e perfeição dos trabalhos;

$3^{\circ}$ Iniciar o ensino profissional de algumas aprendizes.

$\operatorname{Art}^{\circ} 2^{\circ}$ - A oficina divide-se em duas secções: a primeira abrange as obras de agulha e a segunda os trabalhos de pintura. ${ }^{1}$

Regulamento provisório para o ensino profissional na oficina de lavores femininos da Escola Marquês de Pombal, em Alcântara (22 de Outubro de 1886)

Quatro ideias importa reter desta incursão legislativa na área do ensino profissional feminino:

-A primeira passa pelo pioneirismo na área do ensino técnico, uma vez que é a primeira determinação legislativa no ensino secundário que foca de modo particular a formação do ensino feminino (relembremos a propósito dois outros factos - data de 1884/85 o arranque da rede de escolas de desenho industrial e industriais; e a criação de uma secção feminina do ensino liceal só aparecerá em $1906^{2}$ ).

-A segunda remete-nos para a existência de oficinas anexas em várias escolas contemplando formação especificamente feminina - Caldas da Rainha, Covilhã, Lisboa, Torres Novas, Tomar, Portalegre - e "exigindo" uma regulamentação abrangente, como é o caso do Decreto de 23 de Fevereriro de 1888, que se transformou no primeiro documento de organização geral deste sistema de ensino a explicitar "a criança de ambos os sexos" e "adultos dos dois sexos" como destinatários do ensino assegurado pelas escolas industriais e de desenho industrial.

\footnotetext{
${ }^{1}$ Portaria de 22 de Outubro de 1886 aprovando o regulamento provisório para o ensino profissional na oficina de lavores femininos da Escola Marquês de Pombal, em Alcântara. Diário do Governo, no 244 de 26 de Outubro de 1886, p. 751-753.

${ }^{2}$ Referimo-nos ao Decreto de 31 de Janeiro de 1906 que aprova a organização do Liceu Maria Pia em Lisboa que transforma a "Escola Maria Pia, de Lisboa, considerada instituto de instrução secundária para o sexo feminino" em "Liceu Maria Pia" passando a reger-se "pelo regime vigente da instrução secundária". In. Reformas do Ensino em Portugal (1900-1910). Lisboa, Ministério da Educação, 1996, Tomo I - vol. IV, p. 432.
} 
-A terceira evidencia o facto destes casos terem funcionado como exemplos e o percurso até 1910 contemplar não apenas o alargamento dos "lavores femininos" a outras escolas, como determinar mesmo, face à procura, a criação de escolas dedicadas exclusivamente "ao ensino de raparigas" como é o caso de Peniche, especializada na formação de "artistas para fabricar rendas de bilros".

-A quarta esclarece-nos sobre os conteúdos predominantes. Sempre com a preocupação de a formação ter "utilidade prática e aplicações nas indústrias locais", determina-se que na secção de "trabalhos de agulha" para além da execução de bordados e rendas, se aprenda com máquinas de costura, claramente com o objectivo de formar alunas para áreas menos tradicionais, como era o caso da confecção. Na oficina de Pintura a elaboração de trabalhos decorativos contemplava papel, vidro, tecidos, cerâmica, leques, almofadas, pratos, flores de papel, pano, cera e seda, podendo a sua execução ser domiciliária, em unidades oficinais ou em estabelecimentos fabris.

As várias reformas de finais do século XIX e até à República, apesar de algumas indefinições, alinharam no sentido de alargar as oficinas na rede de ensino industrial: entre 1886 e 1910 abriram oficinas em 22 escolas e a partir de 1892/93 o número de escolas com oficinas para o sexo feminino fixou-se acima do registado para o sexo masculino. A afluência de mulheres às oficinas foi surpreendente: das 11789 matrículas registadas entre 1886/87 e 1909/10, mais de metade $(58 \%)$ são do sexo feminino ${ }^{3}$.

\section{REPÚBLICA - ideias e espaços para o ensino feminino}

(...) Na massa dos desprotegidos da sorte há também homens de inteligência viva, arguta e fina, e que se vêm forçados a um trabalho secundário, muitas vezes extenuante, e raros são os que conseguem uma posição razoavelmente lucrativa Muitos deles ocupam no comércio lugares que deveriam ser desempenhados por mulheres.

(...) O caso vem reflectir-se ainda, na miséria moral da sociedade, desviando para outro caminho muitas mulheres que deveriam ter no comércio uma colocação, como elementos de trabalho, enquanto que actualmente só servem para avolumar o chamado peso social.

\footnotetext{
${ }^{3}$ PINTO, Teresa (2009)- As Mulheres no Ensino Industrial Público - dos cursos industriais aos cursos de Lavores Femininos (1884-1910). In "Vértice", II série, Julho-Agosto de 2009, p. 13. 
(Preâmbulo do decreto no 5029 de 1 de Dezembro de 1918) ${ }^{4}$

Deixemos, para já, repousar em paz este pequeno excerto de um dos maiores relatórios justificativos de uma reforma do ensino, alguma vez produzido na nossa abundante legislação.

Recordemos previamente alguns dados contextuais que nos ajudam a caracterizar o ambiente republicano feminino.

Várias organizações - Liga Republicana das Mulheres Portuguesas (1908-1919), por exemplo - associações - Associação de Propaganda Feminista, fundada em 1912 ou o Conselho Nacional das Mulheres Portuguesas, fundado em 1914 - ou simples militantes femininas em nome individual - Ana de Castro Osório, Maria Velleda (de seu verdadeiro nome Maria Carolina Frederico Crispim), Carolina Beatriz Ângelo, Adelaide Cabete, entre muitas outras, reivindicaram para a mulher um tratamento menos segregador, a vários níveis. Casamento e divórcio, direito de voto, igualdade de tratamento nas leis e nas práticas, são algumas das áreas onde investiram mais energias. Pensamos, no entanto, que a todas elas se sobrepuseram as posições assumidas na área educativa. Seja o simples direito à instrução, seja a igualdade de acesso aos níveis superiores de ensino, podemos, na imprensa, nos livros, nas intervenções em Congressos, nos editoriais de muitas revistas específicas, em bibliotecas especificamente criadas para o público feminino, encontrar uma multiplicidade de argumentos que entroncam nas expectativas criadas pelos republicanos.

Respira-se um ambiente onde se sente que "(...)a mulher racionalmente educada tornarse-á uma fada cuja varinha mágica poderia ter o poder sublime de transformar um cancro social em florescente tesouro que favorecia a família e enriqueceria a Pátria"5. Entre finais do século XIX e 1924 (realização em Lisboa do Primeiro Congresso Feminista e da Educação) há um período extremamente rico de fontes e de posições de “contestação feminista aos vícios

\footnotetext{
${ }^{4}$ Relatório do Secretário de Estado João Alberto Pereira de Azevedo Neves. In. "Diário do Governo" no 263, I Série, 5 de Dezembro de 1918, p. 2086. Este Relatório antecede e justifica o Decreto 5029 de 1 de Dezembro que organiza o ensino industrial e comercial.

${ }^{5}$ PATACHO, Emília (1909) - Relatório sobre assuntos de Higiene Especialmente aplicáveis ao Sexo Feminino para o Ensino Normal Primário". In. "Primeiro Congresso Pedagógico da Liga Nacional de Instrução", Lisboa, Imprensa Nacional, 1909, p. 101.
} 
discriminatórios do sistema educativo português e de propostas para uma efectiva implementação da educação feminina"6.

Neste quadro, é possível agora inscrevermos, a proposta de António Arroyo, inspector do ensino industrial e commercial que, em 1911, numa lúcida análise sobre o que urgia fazer esclarecia no tema respeitante ao ensino feminino:

(...) $\mathrm{O}$ ensino feminino, para ser tomado a sério, não prescinde por forma alguma da precedência do inquérito directo aos meios locais, sem o que cairemos fatal e novamente nos eternos trabalhos de mão que faziam a felicidade dos nossos avós. Lançando os olhos para qualquer publicação que se ocupe das várias profissões femininas facilmente podemos extrair dela uma numerosa série de modalidades existentes entre nós, cuja educação técnica reclama a intervenção da escola. ${ }^{7}$

Mais adiante no seu Relatório, Arroyo identifica as áreas/ profissões que necessitavam de uma formação específica de forma a garantir uma adequada preparação profissional para a integração da mulher no mercado de trabalho ou no mundo do empreendedorismo individual. Identifica:

(...) a) No Comércio - Caixa e Escrituração;

b) Nos Trabalhos Manuais, chegando por vezes à fase de invenção artística, Bordados diversos, Coletes de senhora, Costura (vestidos, confecções, roupa branca), Gravatas e Colarinhos, Rendas, Luvas, Modas e Chapeus, Passamanaria, Consertos de roupa, Tapeçaria, Ruches e plissés, Roupa de homem, camisas de homem, etc.

c)Nas profissões diversas - Bandages, Bustos e manequins, Cartonagens, Obra de cabelo, Engomado, Leques (abat-jours e paraventos), Flores artificiais, Encadernação, Penas (obra de), Pintura cerâmica, etc.

d)Na Alimentação - Cozinha, Confeitaria, Conservas, etc.

e)Trabalho Caseiro (...). ${ }^{8}$

Este extenso inventário de cursos que Arroyo reclama para o ensino técnico é importante porque, por um lado esclarece-nos sobre as necessidades profissionais e, paralelamente, sobre o quotidiano e necessidades da sociedade portuguesa do início da República, mas, por outro, ajuda-

${ }^{6}$ GUINOTE, Paulo J.A. (2003) - A Educação no Feminino (1900-2000). Discursos, Números e Olhares. In. CASTRO, Zília Osório de [dir.] (2003) - "Falar de Mulheres - Da Igualdade à Paridade", Lisboa, Livros Horizonte, p. 160.

${ }^{7}$ ARROYO, António José (1911) - Relatórios sobre o Ensino Elementar Industrial e Comercial. Lisboa, Imprensa Nacional, p. 141

${ }^{8}$ Idem. 
nos também a confrontar esta proposta de alguém extremamente respeitado pelo poder político e depois a realidade implementada. Para avançarmos desde já nessa comparação, regressemos à nossa frase incial que deixamos em repouso. Realmente, está muito longe o que pensam os verdadeiros conhecedores do sistema de ensino, dos decisosres políticos de 1918. Uns visam, através da instrução, fornecer armas à mulher para encarar o mundo profissional com preparação, qualificação e até autonomia. Outros consideram que as profissões são determinadas em função do sexo, remetendo para as mulheres, aquelas de que nem todos os homens são dignos. Uns, conhecendo a realidade europeia, particularmente a francesa, austríaca ou belga, procuram criar uma dinâmica instrutiva que profissionalize as mulheres, fornecendo-lhe os meios para uma emancipação económica e social. Outros discriminando cursos consoante os sexos e apostando num segmento profissional exclusivamente feminino.

Apesar de tudo, temos de olhar às realidades que a $\mathrm{I}^{\mathrm{a}}$ República nos trouxe, tanto em termos de rede de ensino técnico, quer em termos de adesão feminina.

Comecemos pelas indicações que as medidas tomadas nos permitem inferir.

\section{Espaço da mulher na "sementeira legislativa"}

Os governos da República, assumindo o pensamento veiculado por vários republicanos desde Rodrigues de Freitas a Bernardino Machado ou João de Barros - vão tratar com invulgar cuidado a instrução e, no caso do ensino técnico, dar-lhe uma nova orientação pedagógica e um novo "conteúdo" de molde a contribuir para o progresso e desenvolvimento económico do País e profissional dos seus alunos e alunas.

Olhando para a riqueza e profusão legislativa da República, importa-nos desde logo destacar que as medidas tiveram por suporte, quase sempre, estudos e relatórios existentes ou solicitados pelos diferentes governos. O positivismo republicano exigia que as inciativas fossem devidamente explicadas e fundamentadas. Desde os Relatórios já referidos de António Arroyo, até artigos na imprensa de António Sérgio, Bento Carqueja ou Laurindo Costa, ou publicações ${ }^{9}$ como a de António Aurélio da Costa Ferreira na sequência da sua passagem pelo Ministério do Fomento (donde dependia o ensino técnico), toda a informação é importante para esclarecer o

\footnotetext{
${ }^{9}$ Refiro-me por exemplo a FERREIRA, A. Aurélio da Costa (1914) - Alguns documentos concernentes à minha passagem pelo Ministério do Fomento. Lisboa.
} 
sentido das medidas que se implementam. Paralelamente são nomeadas múltiplas equipas ou comissões para analisarem a situação e proporem medidas objectivas a implementar, a par de vários inquéritos de natureza económica para se perceber, por localidade, quais as formações (e cursos profissionais) que seriam mais necessários. Esta preocupação pela objectividade, pelas decisões com fundamentos sistematizados, pela informação estatística, fornece uma quantidade de dados que ajudam a perceber o sentido em que se pretendia legislar, mas também um quadro do País que a República tinha herdado e onde queria agora intervir.

Destaquemos algumas iniciativas no que diz respeito ao ensino técnico feminino. $\mathrm{O}$ Decreto 615 de 30 de Junho de 1914, legislando sobre o ensino comercial, cria, de forma pioneira, um curso de "empregadas de escritório" procurando abrir a porta dos serviços às mulheres e evitando, pela via da sua formação, o seu afastamento para actividades e funções de menor valia. Referir ainda que os conteúdos do curso apostavam em "serviços de correspondência, arquivo e expediente", "língua inglesa", "estenografia” e "escrituração". Aliás este curso vem na sequência da criação de cursos livres de estenografia e dactilografia, gratuitos em várias escolas ${ }^{10}$.

Algumas escolas particulares, apostam também na formação feminina, criando cursos específicos - por exemplo de Economia Doméstica -, permitindo a coeducação em cursos, sobretudo da área comercial, ou facultando a possibilidade de inscrição em disciplinas isoladas, claramente uma forma de se adquirir conhecimentos específicos sem a preocupação da certificação por curso. Nesta última opção, verfica-se a inscrição em disciplinas como Cálculo, Caligrafia, Contabilidade, Dactilografia, Estenografia, Inglês, Francês, entre outras ${ }^{11}$.

Alfredo Magalhães, na sua passagem pelo governo, decreta em 3 de janeiro de 1918, a existência de trabalhos manuais em todas as escolas do País, para o sexo feminino. Paralelamente, nomeia 11 comissões para analisarem os serviços e os graus de ensino público em Portugal, propondo, na sequência dos diagnósticos, medidas a implementar. A $V^{\text {a }}$ Comissão integrava vários directores de Escolas Comerciais e Industriais e era presidida por Alfredo Bensaúde, director do Instituto Superior Técnico. Os resultados deste trabalho serviu como

\footnotetext{
${ }^{10}$ CARDIM, José Eduardo de Vasconcelos Casqueiro (2005) - Do Ensino Industrial à Formação Profissional. As políticas públicas de qualificação em Portugal. Lisboa, Universidade Técnica de Lisboa, Volume 1, p. 384.

${ }^{11}$ VIEIRA, Mário Lázaro Santos (2010)- A Escola Prática Comercial Raul Dória: Memória de um espaço de Ensino Comercial (1902-1964). Porto, FLUP, p. 136-137 (Dissertação de Mestrado em História e Educação).
} 
referência (embora em muitos casos distante das propostas apresentadas) para a Reforma de referência da $1^{\text {a }}$ República, decretada em 1 de dezembro de 1918 por João Alberto Pereira de Azevedo Neves.

Nessa reforma, aposta-se na remodelação para o desenvolvimento e na difusão do ensino técnico, estabelecendo-se as bases para a criação de novas escolas industriais e elementares de artes e ofícios, aulas de comércio, criação de cursos especializados destinados a artistas, mestres de oficina, planos de cursos de trabalhos manuais e de lavores femininos, oficinas para diversos ramos de profissões.

O plano do ensino técnico e profissional passava pelo industrial (ministrado em escolas de artes e ofícios, industriais, preparatórias - para o acesso aos Institutos - de arte aplicada e Institutos Industriais ou Instituto Superior Técnico) e pelo técnico comercial (ministrado em aulas comerciais, escolas elementares de comércio e Institutos). Em nenhum deles há qualquer discriminação no acesso no respeitante ao sexo e, para as escolas industriais, preparatória e de arte aplicada, esclarece-se no artigo 24 que essas escolas "serão destinadas a indivíduos dos dois sexos que tenham obtido a aprovação no exame de grau complementar da instrução primária”. Num parágrafo único a este artigo, acrescenta-se que "quando as necessidades locais ou o movimento escolar o tornarem indispensável poderão estabelecer-se escolas de qualquer dos tipos separadamente" ${ }^{\prime 2}$. Nas escolas comerciais, o artigo 193 alinha por texto idêntico no que diz respeito à admissão e no seu parágrafo $4^{\circ}$ volta a reiterar que "quando a frequência das escolas o tornar necessário poderá o Governo estabelecer escolas destinadas exclusivamente a um dos sexos"13.

Nas escolas industriais, onde havia cursos de aprendizagem com três graus (preliminar destinado a "estabelecer a ligação com a escola primária"-, geral - "destinado á formação de aprendizes" - e complementar - "destinado à formação de operários"), no primeiro, entre as diversas disciplinas aparece "noções de costura, bordados, rendas e cartonagem, para o sexo feminino" ${ }^{\prime 14}$.

\footnotetext{
${ }^{12}$ Decreto 5029 de 1 de Dezembro de 1918. In. "Diário do Governo" nº 263, I Série, 5 de Dezembro de 1918, p. 2091.

${ }^{13}$ Idem, p. 2103.

${ }^{14}$ Idem, p. 2091 e 2092.
} 
Nos Institutos Superiores, tanto industriais como comerciais, não há qualquer articulado de natureza discriminatória, embora se utilize sempre a designação "aluno" nos diplomas.

Ainda no âmbito das iniciativas republicanas merecem destaque dois apontamentos mais pelo relevo dado à inclusão do sexo feminino dentro das preocupações legislativas.

Um primero tem a ver com o regulamento das Escolas Primárias Superiores, publicado em 10 de maio de 1919, que refere, logo no art $^{\mathrm{o}} 1^{\mathrm{o}}$ que "as escolas primárias superiores são institutos de educação geral e de preparação técnica de carácter regional" e no parágrafo único assinala que "o seu regime é o da coeducação". Este termo é tanto mais importante quanto é raro o seu aparecimento nas iniciativas republicanas, sendo o seu conteúdo e a sua implementação extremamente discutida em vários locais de opinião: debates, artigos, congressos, imprensa. Refira-se ainda que estas Escolas tinham "secções técnicas" (comercial, agrícola, doméstica, industrial ou maritima) cabendo ao Governo, "atendendo aos interesses técnicos de cada região" a designação das secções a funcionar. Apesar da reduzida adesão a este nível de ensino, não deixa de ser significativo ao nível dos princípios, este tratamento "inclusivo".

Um outro apontamento merece a "Proposta de Lei sobre a Reorganização da Educação Nacional" apresentada pelo Ministro João José da Conceição Camoesas, em 21 de Junho de 1923, à Câmara dos Deputados. Refira-se desde já que esta proposta não passou disso e, tal como muita da legislação aprovada durante a $1^{\mathrm{a}}$ República, ficou como mera manifestação da incapacidade de transformar ideias generosas em realidades concretas. Ela é também importante porque remete-nos, a três anos do fim da República, para o dominío das intenções e promessas não cumpridas pelos republicanos. Nessa proposta assume-se que "está por fazer a educação da mulher em termos do seu rendimento doméstico e social". Mais adiante refere que "não existe a educação técnica da mulher com prejuízo da sua missão própria, doméstica e económica". Depois de um diagnóstico que ocupa seis páginas do Diário do Governo ${ }^{15}$ avança com algumas propostas que repetem ideias e princípios anteriores a 1910: "a coeducação" como princípio a seguir desde a educação infantil. Os liceus femininos de Lisboa, Porto e Coimbra deviam converter-se em Escolas Técnicas complementares para a educação das actividades profissionais e sociais da mulher e teriam as seguintes secções: comercial, industrial (desenho especializado, costura e corte, lavores, rendas, bordados, modas, chapéus, taquigrafia e dactilografia), artística (desenho,

${ }^{15}$ Diário do Governo, no 151, II ${ }^{\mathrm{a}}$ Série, 3 de Julho de 1923, p. 2258 a 2271. 
modelação, pintura, flores artificiais, música e canto) e de enfermagem (higiene, puericultura, pedagogia e enfermagem). Defendia-se também a criação de um internato modelo masculino e outro feminino segundo o "tipo das escolas novas" com o curso geral e especial do ensino secundário e "as secções que forem convenientes das Escolas Técnicas elementares e complementares". Na base 14, quando refere as Escolas Normais Primárias, sugere a criação de uma secção para "formação de jardineiras de infância" (única onde o substantivo surge no feminino, já que para todos os outros graus de ensino é o masculimno o utilizado).

É visível nesta proposta, algumas das ideias que encontramos em 1911 (por exemplo nos relatórios do Inspector António Arroyo) mas também algumas indefinições e até contradições sobre o sentido de igualdade que destinavam ao sexo feminino

Destes princípios e ideias, passemos agora a alguns dados de natureza quantitativa, para percebermos melhor o nível de feminização do ensino em geral, e em particular do técnico, e o tipo de adesão que as estudantes tiveram a esta vertente educativa.

\section{Espaço da mulher nas estatísticas educativas}

Uma ideia inicial usando as palavras de Alice Samara:

(...) A grande maioria das mulheres não nos deixou a sua opinião, os seus pensamentos, as suas análises sobre o mundo que as rodeava, sobre si mesmas enquanto género ou enquanto classe. Apenas as mulheres letradas podem escrever e publicar memórias. E a esmagadora maioria das mulheres deste período é analfabeta $(\ldots) .{ }^{16}$

Esta realidade serve-nos de mote para esclarecermos alguns aspectos, exemplificar com alguns dados e, espero, ficarmos com uma visão da presença feminina nos diversos graus de ensino, particularizando o caso do técnico.

Um dos aspectos que realça na primeira república é a existência de alguma anarquia na sistematização dos dados estatísticos, os critérios que são utilizados e os hiatos a que o Anuário Estatístico de Portugal não consegue responder.

\footnotetext{
${ }^{16}$ SAMARA, Maria Alice (2007) - Operárias e Burguesas. As Mulheres no Tempo da República. Lisboa, A Esfera dos Livros, pp. 9 e 12. 
Entronca neste problema um outro que passa pela reduzida preocupação, nos dados inventariados, com a divisão entre "varões"" e "fêmeas", surgindo em muitos casos apenas o total de alunos.

A ausência de estudos monográficos com alguma expressão, a par de alguma desorganização no Arquivo Histórico do Ministério da Educação relativamente ao ensino técnico, em particular, impedem o confronto de informações e o rigor que seria de exigir.

Ultrapassadas as desculpas, importa avançarmos com os dados que evidenciam os aspectos a que nos comprometemos.

Numa visão transversal, teremos de começar pela base - taxas de alfabetização evidenciando que, entre 1900 e 1930, passa-se no total de $27 \%$ para $40 \%$, sendo que a masculina sobe 14 pontos (de 36 para 50\%) e a feminina salta de 18 para 31\% (Quadro 1 e Gráfico 1).

Quadro 1 - Dados da taxa de alfabetização entre 1900 e 1930). ${ }^{17}$

\begin{tabular}{|l|l|l|l|l|}
\hline & $\mathbf{1 9 0 0}$ & $\mathbf{1 9 1 1}$ & $\mathbf{1 9 2 0}$ & $\mathbf{1 9 3 0}$ \\
\hline Taxa de Alfabetização Total & 27,0 & 31,0 & 35,0 & 40,0 \\
\hline Taxa de Alfabetização Masculina & 36,0 & 40,0 & 44,0 & 50,0 \\
\hline Taxa de Alfabetização Feminina & 18,0 & 23,0 & 27,0 & 31,0 \\
\hline
\end{tabular}

Gráfico 1 - Evolução da população alfabeta em Portugal entre 1900 e $1930^{18}$

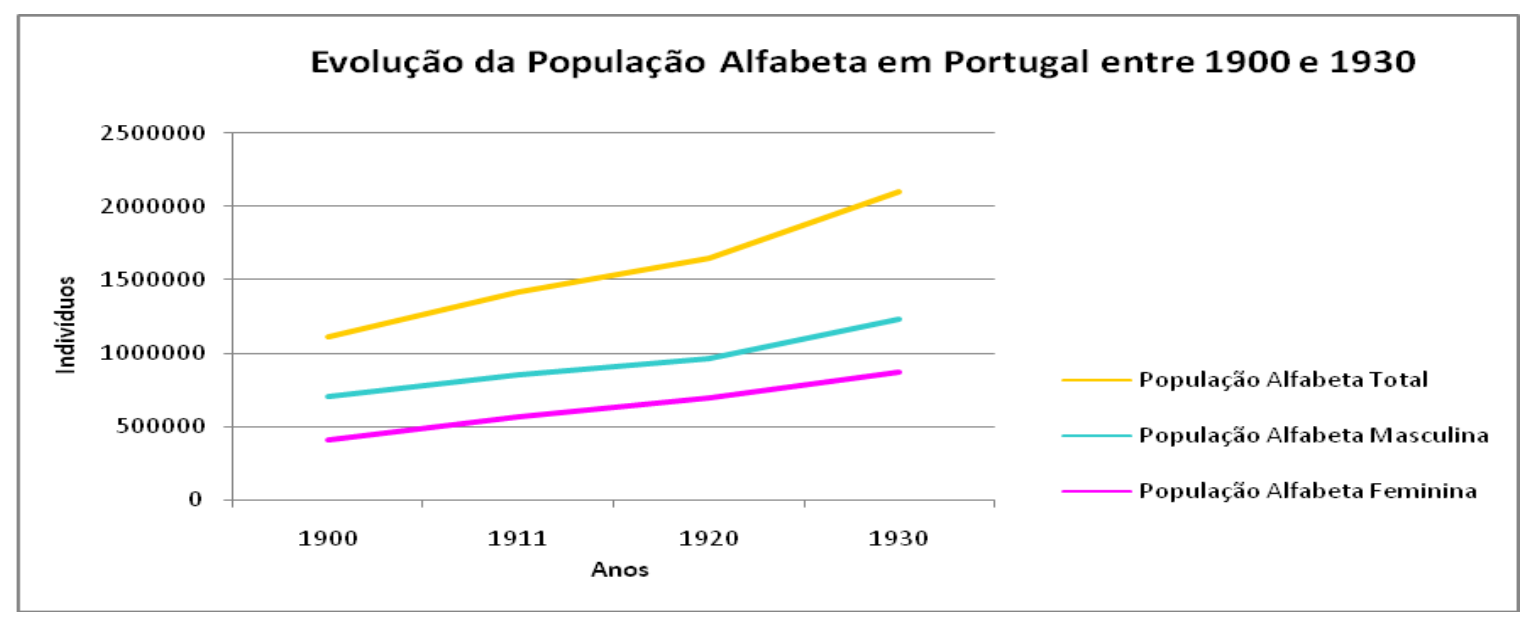

${ }^{17}$ Dados retirados de CANDEIAS, António (dir. e coord.), PAZ, Ana, ROCHA, Melânia - Alfabetização e Escola em Portugal nos Séculos XIX e XX - Os Censos e as Estatísticas. Lisboa, Fundação Calouste Gulbenkian, 2004, p. $112,120,137$ e 147.

${ }^{18}$ Dados retirados de CANDEIAS, António (dir. e coord.), PAZ, Ana, ROCHA, Melânia - Alfabetização e Escola em Portugal nos Séculos XIX e XX - Os Censos e as Estatísticas. Lisboa, Fundação Calouste Gulbenkian, 2004, p. $112,120,137$ e 147. 
Se alguma ideia nos parece evidente é a exasperante lentidão do crescimento do número de alfabetizados durante o período da República, independentemente do seu crescimento.

Para este aumento há um papel importante desempenhado pelas Escolas Móveis e, neste particular, nota-se uma honrosa permanência do sexo feminino na sua frequência com a curiosidade de existirem escolas apenas femininas e um número significativo de mistas (por exemplo, mesmo num período difícil como foi o de 1917/1918, num total de 229 escolas, 68 eram femininas e 161 mistas). O gráfico 2 evidencia a maior regularidade da frequência feminina.

Gráfico 2 - Evolução do no de alunos matriculados nas escolas móveis - 1910-1930 ${ }^{19}$

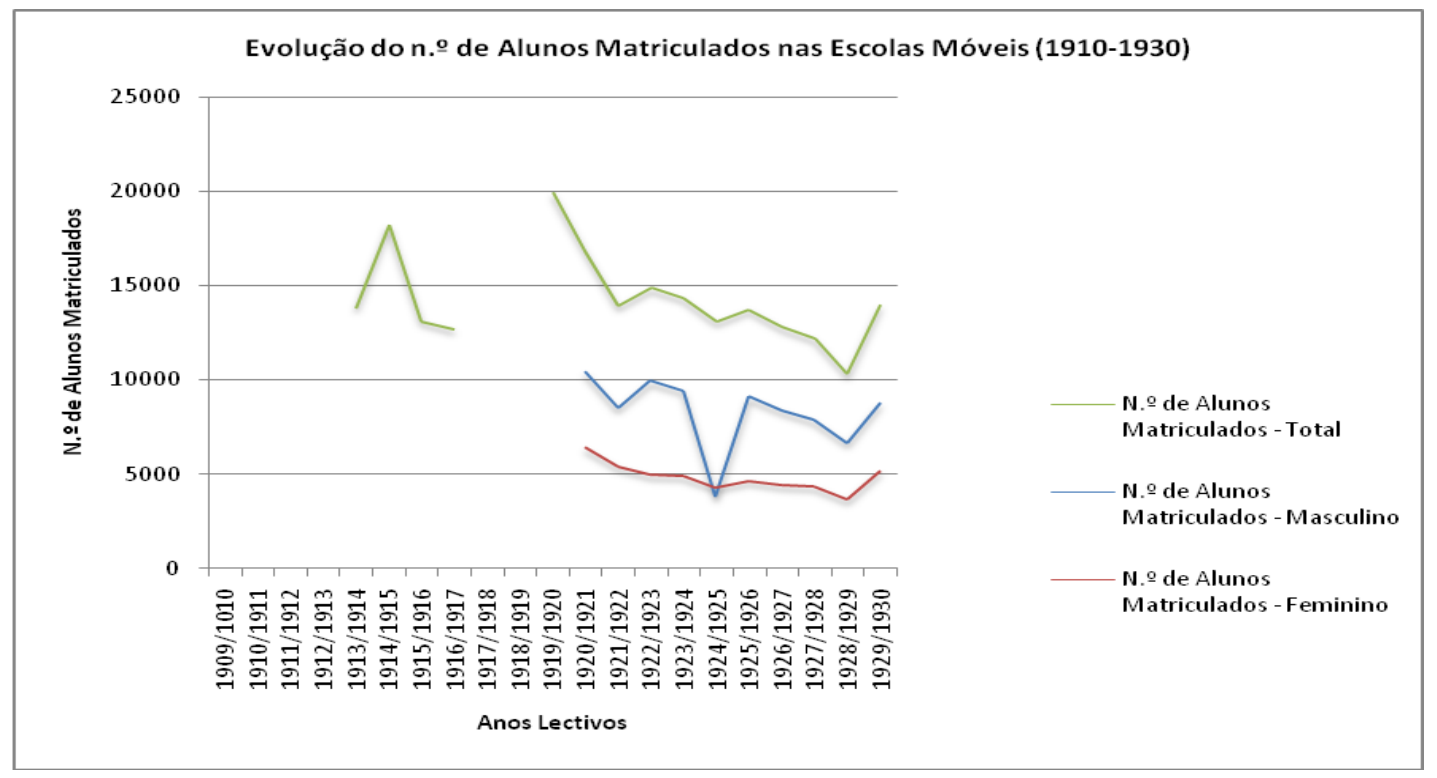

No ensino liceal, apesar da enorme distância na frequência, não há um grande crescimento da procura feminina, embora seja normalmente aceite que o recato e controle do ensino particular inspirava mais confiança às famílias para aí colocarem as suas filhas. Infelizmente os dados disponíveis não permitem avançar aí com rigor. No gráfico 3 selecionamos aqueles anos lectivos para os quais temos dados comparativos.

\footnotetext{
${ }^{19}$ Anuário Estatístico de Portugal - anos de 1905-1910, 1917, 1919, 1921, 1923, 1924, 1925, 1926, $1927,1928,1929$ e 1930. Lisboa, Imprensa Nacional. 
Gráfico 3 - Evolução do no de alunos no ensino liceal $(1910 \text { - 1930 })^{20}$

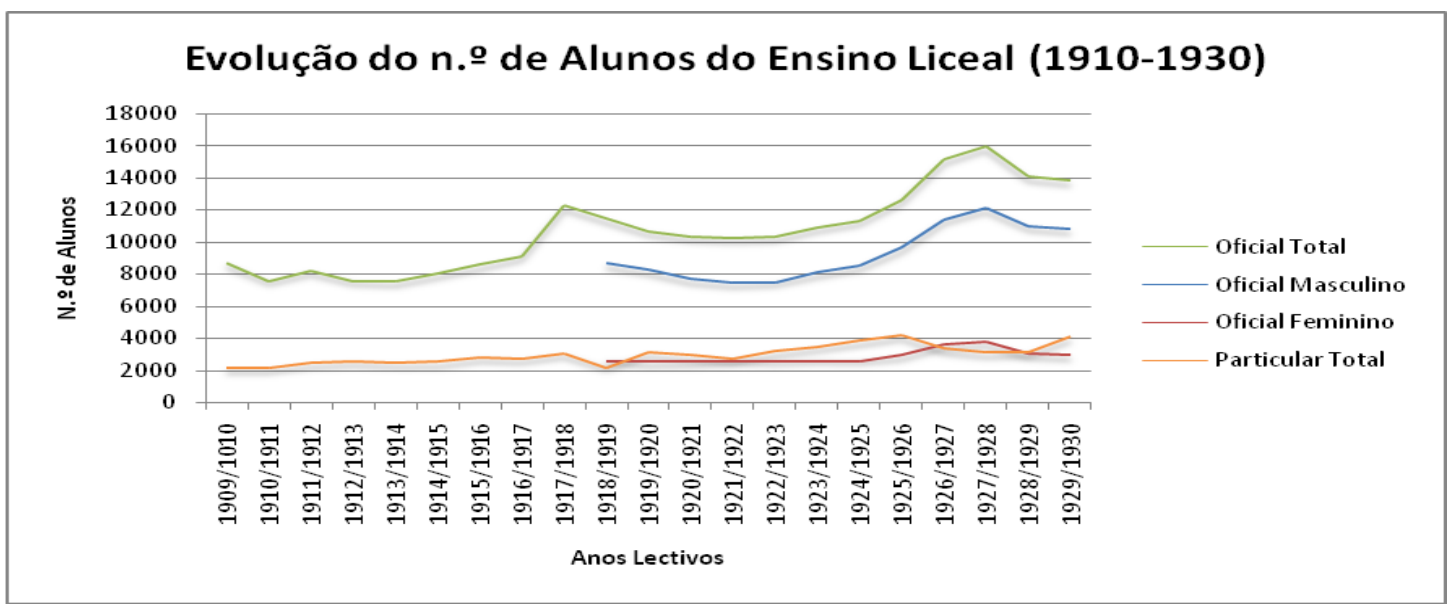

Este introito estatístico, serve sobretudo para podermos agora compreender a singularidade ou a normalidade dos dados relativos ao ensino técnico.

Numa primeira nota importa dizer que este subsistema foi, por um lado, aquele onde mais se fizeram sentir algumas das dúvidas sobre educação feminina durante a $1^{\text {a }}$ República mas, por outro, onde a realidade se mostrou mais avançada do que podíamos imaginar, olhando às polémicas que sempre envolveram a sua formação no âmbito do sistema educativo.

Onde houve mais dúvidas porque há cursos que são criados, no ensino oficial e até particular, destinados especificamente à mulher e que se revelaram ou um fracasso - por exemplo o de economia doméstica - ou um sucesso - caso das oficinas das escolas de desenho industrial. Há cursos especiais que são criados nas escolas industriais - por exemplo o de Lavores Femininos que têm logo grande adesão. No segmento temporal de 1914/1919, apesar de coincidir com a $1^{\text {a }}$ Guerra Mundial, verifica-se uma tendência que é também visível no período em estudo: a adesão feminina foi sempre maior nos trabalhos oficinais do que nas disciplinas que constituíam os cursos estruturados em formação mais geral e técnica. O Gráfico 4 evidencia este aspecto.

${ }^{20}$ Anuário Estatístico de Portugal - anos de 1905-1910, 1917, 1919, 1921, 1923, 1924, 1925, 1926, 1927, 1928, 1929 e 1930. Lisboa, Imprensa Nacional. 
Gráfico 4 - Evolução do no de alunos nas Escolas de Desenho Industrial (1914-1919) distribuídos por tipo de ensino e sexo ${ }^{21}$

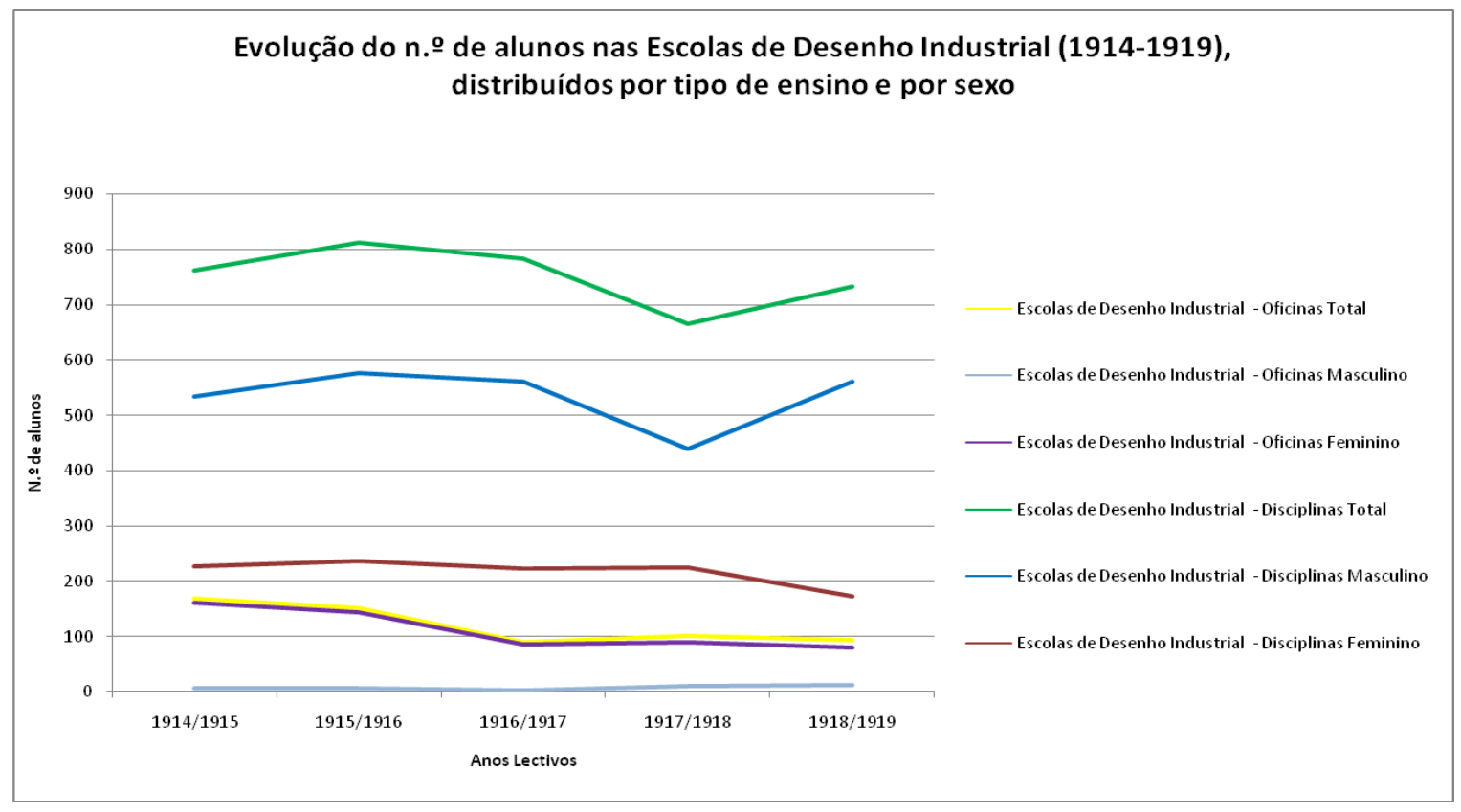

Numa posição mais equilibrada encontramos as escolas elementares de comércio, onde é visível uma presença feminina ao longo da República com números cada vez mais significativos, apesar de alguma irregularidade: de 29 alunas em 1910/1911 passamos para 542 em 1920/1921, embora a década tenha terminado com 251 inscritas (Gráfico 5).

${ }^{21}$ Anuário Estatístico de Portugal - anos de 1905-1910, 1917, 1919, 1921. Lisboa, Imprensa Nacional. 
Gráfico 5 - Evolução do nº de alunos nas Escolas Elementares de Comércio (1910/1911 a $1929 / 1930)^{22}$

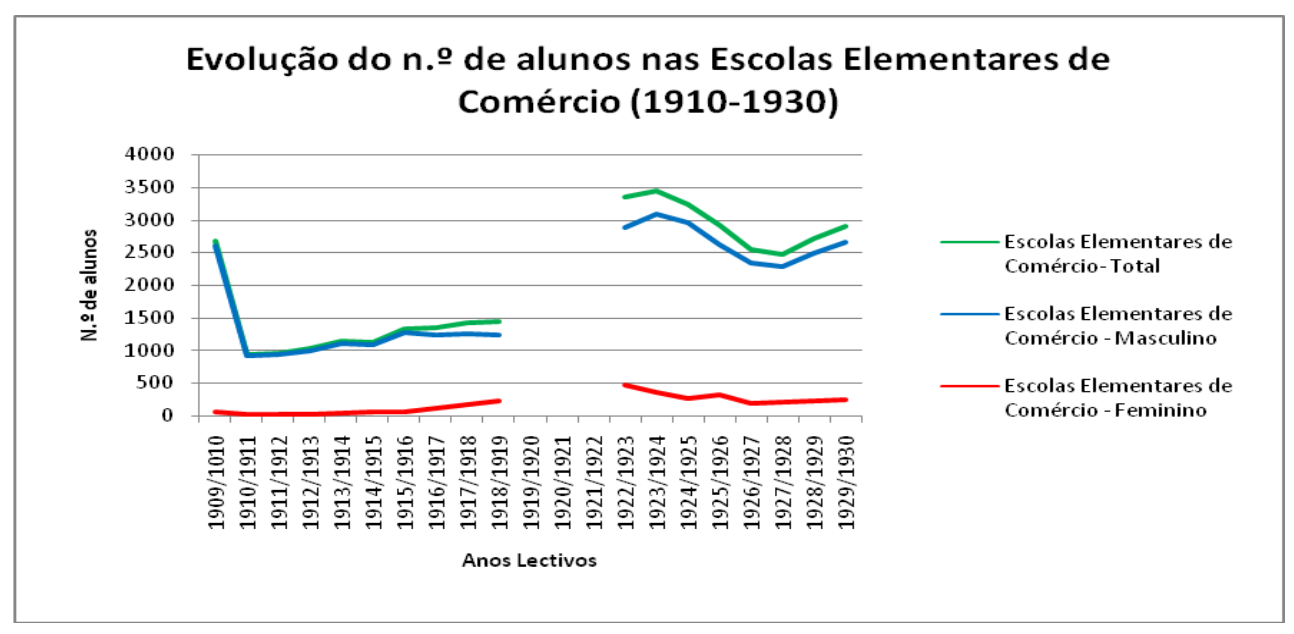

Da realidade avançada podemos falar quando na década de 1920, em todas as escolas industriais e de desenho industrial se nota uma crescente frequência feminina: nas preparatórias (para acesso ao ensino médio ou superior, em particular de Comércio), nas industriais e industriais e comerciais ${ }^{23}$, nas de artes e ofícios ${ }^{24}$ e nas de arte aplicada ${ }^{25}$, embora aqui com menor expressão.

\footnotetext{
${ }^{22}$ Anuário Estatístico de Portugal - anos de 1905-1910, 1917, 1919, 1921, 1923, 1924, 1925, 1926, 1927, 1928, 1929 e 1930. Lisboa, Imprensa Nacional.

${ }^{23}$ As escolas industriais destinam-se "a preparar aprendizes em cursos de aprendizagem e operarios em cursos de aperfeiçoamento". As "escolas comerciais serao estabelecidas pelo Governo nos centros comerciais importantes e serao destinadas a ministrar o ensino elementar commercial aos que se preparam para a entrada nas carreiras comerciais e de aperfeiçoamento para os empregados de comercio". Decreto 5029 de 1 de Dezembro de 1918. In. "Diário do Governo" n 263, I Série, 5 de Dezembro de 1918, p. 2091 e 2103

24 "As escolas de artes e ofícios serão destinadas a ministrar o ensino elementar, sob uma forma inteiramente prática e acessível aos indivíduos que se consagram às profissões artísticas e industriais e que não puderam adquirir os conhecimentos gerais dados pela instrução primária elementar e poderão admitir, até, à sua frequência indivíduos analfabetos". Idem, p. 2090.

${ }^{25}$ Destinam-se ao "ensino especializado de artes industriais". Idem, p.2 091.
} 
Quadro 2- Frequência entre 1920 e 1930 nas diferentes escolas

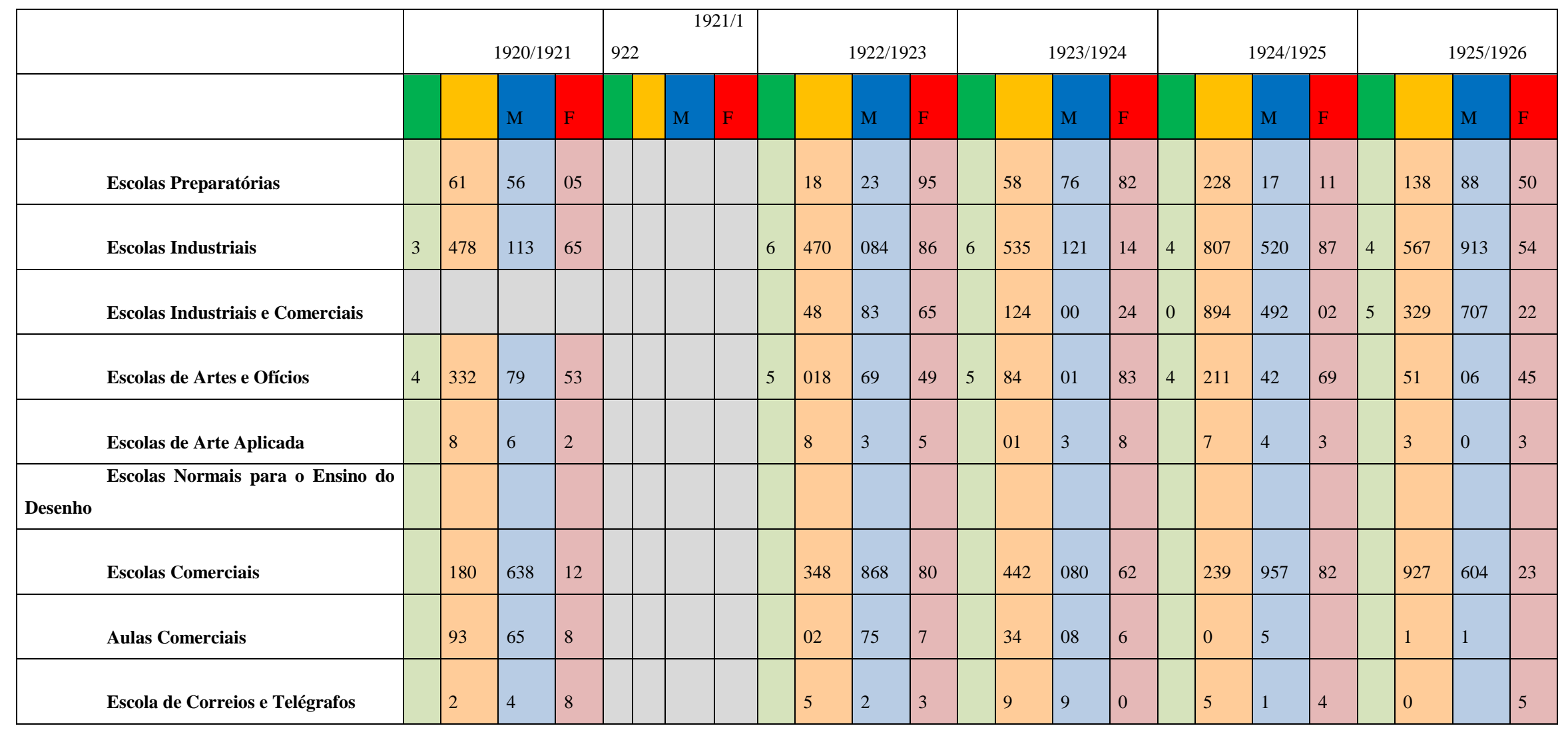

\section{Fillistornias}




\begin{tabular}{|c|c|c|c|c|c|c|c|c|c|c|c|c|c|c|c|}
\hline & \multicolumn{3}{|c|}{$1926 / 1927$} & \multicolumn{4}{|c|}{$1927 / 1928$} & \multicolumn{4}{|c|}{$1928 / 1929$} & \multicolumn{4}{|c|}{$1929 / 1930$} \\
\hline & & M & $\mathrm{F}$ & & & M & $\mathrm{F}$ & & & M & $\mathrm{F}$ & & & M & $\mathrm{F}$ \\
\hline Escolas Preparatórias & 696 & 352 & 44 & & 702 & 328 & 74 & & 85 & 53 & 32 & & 625 & 114 & 11 \\
\hline Escolas Industriais & 051 & 332 & 19 & 2 & 066 & 308 & 58 & 2 & 698 & 699 & 99 & 3 & 902 & 058 & 44 \\
\hline Escolas Industriais e Comerciais & 293 & 477 & 16 & 9 & 264 & 079 & 185 & 9 & 878 & 458 & 420 & 0 & 210 & 820 & 390 \\
\hline Escolas de Artes e Ofícios & 67 & 03 & 64 & 2 & 177 & 35 & 42 & 1 & 187 & 62 & 25 & & 73 & 48 & 25 \\
\hline Escolas de Arte Aplicada & 3 & 9 & 4 & & 14 & 0 & 4 & & 36 & 05 & 1 & & 50 & 07 & 3 \\
\hline \multicolumn{16}{|c|}{ Escolas Normais para o Ensino do Desenho } \\
\hline Escolas Comerciais & 537 & 333 & 04 & & 476 & 267 & 09 & & 727 & 478 & 49 & & 905 & 654 & 51 \\
\hline Aulas Comerciais & & & & & 3 & & & & 0 & & & & & & \\
\hline Escola de Correios e Telégrafos & 05 & 6 & 9 & & 0 & 2 & & & & & & & 0 & 0 & \\
\hline $\begin{array}{r}\text { Fonte: Anuário Estatístico } \\
\text { 1923, 1924, 1925, 1926, 1927, 1928, }\end{array}$ & $\begin{array}{l}\text { anos de } \\
\text { isboa, Imp }\end{array}$ & $\begin{array}{l}5-19 \\
\text { isa } \mathrm{N}\end{array}$ & iona & & 9,1 & & & & & & \multicolumn{5}{|c|}{$\begin{array}{l}\text { Legenda: } \\
\text { E - N.o de Escolas } \\
\text { A - N.o total de Alunos } \\
\text { AM - Alunos Do sexo masculino } \\
\text { AF - Alunos do sexo feminino }\end{array}$} \\
\hline
\end{tabular}

\section{Fillistónias}


Mas há um exemplo que evidencia de forma clara essa grande adesão às novas profissões por parte do público feminino. Refiro-me à frequência da Escola de Correios e Telégrafos (curso criado em 14 de Janeiro de 1920) que tem desde o início uma grande adesão feminina, ultrapassando nalguns anos lectivos a presença masculina (em 1924/1925, por exemplo, há 21 alunos e 44 alunas). Estranhamente no final da década não encontramos já qualquer aluna inscrita, embora a própria escola esteja em perda de significado (tendo chegado a ter 105 alunos em 1926/1927, e em 1929/1930 tem apenas 30).

Gráfico 6 - Frequência entre 1920 e 1930 nas diferentes escolas ${ }^{26}$

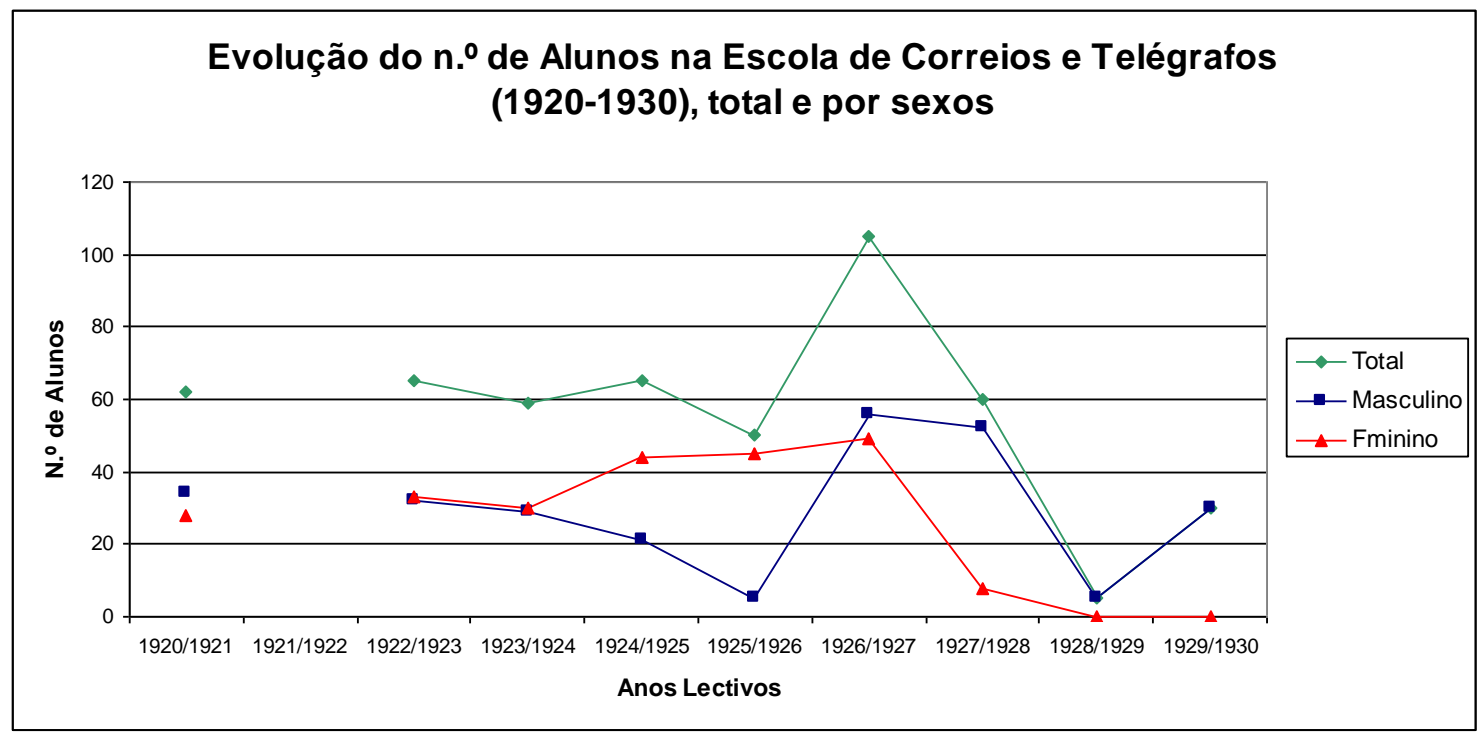

${ }^{26}$ Anuário Estatístico de Portugal - anos de 1905-1910, 1917, 1919, 1921, 1923, 1924, 1925, 1926, 1927, 1928, 1929 e 1930. Lisboa, Imprensa Nacional. 
Estes dados irregulares, mostram também duas evidências: por um lado o ensino técnico procurava ser um espaço educativo de acordo com as novas realidades económicas e sociais; por outro, e talvez por isso, é o subsistema que mais alterações legislativas teve no curto espaço da República. O anexo que colocamos, sem ser exaustivo, dá uma boa amostra dessa instabilidade/indefinição.

Mesmo neste ambiente conturbado e instável, é para nós claro que a taxa de adesão feminina foi sempre muito significativa, umas vezes ligada a actividades específicas - lavores, costura, rendas, bordados... - mas outras mostrando novos espaços profissionais para a inserção no Mercado de trabalho da mulher - caso dos correios e telégrafos mas também do comércio.

Uma última palavra para os Institutos. Tanto relativamente aos Industriais como aos Comerciais faltam estudos monográficos que permitam desagregar os totais de alunos que nos aparecem nas Estatísticas oficiais. Pontualmente conhecem-se vários casos de matrículas de alunas nos comerciais, e a primeira mulher de que temos registo no Industrial do Porto é da década de 1940.

Situação diferente se regista no ensino superior onde, desde 1884/1885, temos notícias de inscrições de alunas, por exemplo na Académica Politécnica - Maria Leite da Silva Tavares Paes Moreira matriculou-se nesse ano para frequentar duas cadeiras: Física e Química Natural (duas das cadeiras preparatórias para o ingresso na Escola Médico-Cirúrgica ${ }^{27}$. Ciências e Medicina foram as duas únicas áreas científicas que receberam matrículas de mulheres, no Porto. Nesse aspecto a $1^{\text {a }}$ República, devido também ao alargamento deste grau de ensino, tanto em termos espaciais como em áreas cientificas, vai assistir à presença de mulheres em Ciências, em Medicina, em Farmácia, em Engenharia e em Letras. Fora do Porto, os exemplos da médica ginecologista Adelaide Cabete (1867-1935) ou de Domitila Hormizinda Miranda de Carvalho (1871-1966) - que acumulou três cursos: Matemática (1894), Filosofia (1895) e Medicina (1904) - tirados na tradicional Universidade de Coimbra, podem ser apontados como paradigmáticos de uma insatisfação da mulher perante o estatuto que lhe estava reservado, mas também como exemplificativos de uma maior entrada do sexo feminina nos diversos graus de ensino.

\section{Conclusão}

(...) As sociedades modernas, ao assinalarem à mulher o lugar proeminente que lhe compete na função social, compreenderam que ele só pode ser digna e

\footnotetext{
${ }^{27}$ SANTOS, Cândido dos ( 1991) - A Mulher e a Universidade do Porto. Porto, Universidade do Porto, p. 11.
} 
convenientemente ocupado quando a mulher estiver munida de uma sólida educação onde sejam aproveitadas todas as suas grandes aptidões e realçadas todas as suas virtudes. Estão as sociedades, com afinco, reparando a injustiça de séculos que lhes negou a robusta e sã educação da inteligência e vêm operando uma revolução pacífica e fecunda. Abrem-se as portas de todas as escolas às mulheres. ${ }^{28}$

Em 1926 não seria muito diferente o discurso, as intenções, mas a margem de tolerância já era menor.

Várias vezes ao longo da República, diversas organizações chamaram a atenção para o pouco que se estava a fazer para corporizar os anseios de instrução por parte da mulher. Refiramse a título de exemplo as intervenções organizadas da Liga Republicana das Mulheres Portuguesas (LRMP) fundada em 1909 e que vai ter um papel activo até 1919, ou o Conselho Nacional das Mulheres Portuguesas que organiza dois excelentes congressos com particular incidência na educação em 1924 e 1918.

Mas destaque-se também as iniciativas individuais de Carolina Beatriz Ângelo, Adelaide Cabete, Ana Castro Osório, Maria Carolina Frederico Crispim (mais conhecida por Maria Veleda ou a"feminista vermelha"), Alice Pestana, Carolina Michaelis de Vasconcelos, Olga Morais Sarmento ou Maria O’Neill.

Nesta vertente - educação da mulher - como em muitas outras as intenções deram lugar a grandes desilusões, em particular pelas expectativas defraudadas em 16 anos de República. Dando consistência a vozes femininas, vários deputados colaboraram nesse desencanto, em particular porque das ideias defendidas às práticas houve sempre a distância parecida com uma utopia. Ouçamos por exemplo a intervenção de Ribeiro de Carvalho na Câmara dos Deputados, em 26 de março de 1914:

(...) Cuidemos apenas doutro problema de fácil resolução e que tenderá prática e beneficamente para a emancipação da mulher. (...) Octávio Bunge, em um estudo notabilissimo diz que essa questão da educação da mulher moderna apresenta principalmente duas fases: a educação feminina e a educação profissional, isto é, a instrução especial para a vida do lar e a instrução profissional para a vida social (...). Um dos aspectos mais importantes do gravíssimo problema da educação e da instrução em Portugal, tem, a meu ver, esta solução fácil: para o homem, a transformação de todas as nossas escolas industriais em verdadeiros institutos de

\footnotetext{
${ }^{28}$ Preâmbulo do Decreto de 31 de Janeiro de 1906 que cria o Liceu Maria Pia para o sexo feminino. In. Reformas do Ensino em Portugal (1900-1910). Lisboa, Ministério da Educação/Secretaria Geral, 1996, Tomo I, Vol. IV. $2^{a}$ parte, p. 429.
} 
artes e ofícios e para a mulher a criação de institutos de ensino profissiuonal e doméstico $(\ldots) .^{29}$

Afinal as facilidades converteram-se em dificuldades e impossiblidades mas, mesmo assim, a mulher conseguiu encontrar um espaço em todos os graus de ensino, destacando aqui o ensino técnico como o subsistema onde a mulher teve sempre um espaço próprio (sobretudo em termos de oficinas), onde o regime de coeducação efectivamente se praticou e onde se conseguiu perceber a sua adesão a cursos novos que traziam as marcas de um novo profissionalismo - em particular tenho em mente o curso de Correios e Telégrafos (que vai dar origem a um papel muito especial das telefonistas no Estado Novo) e aos cursos Comerciais particularmente de secretariado, onde foi visível a sua enorme adesão.

Ou seja, se a entrada da mulher no mundo do trabalho encontrou duas vias privilegiadas as oficinas, as manufacturas, as indústrias que exigiam um capital humano numeroso e mal remunerado, mas também o sector dos serviços - foi no ensino técnico que a mulher melhor encontrou a via formativa para a sua afirmação nesses espaços laborais - tanto os mais tradicionais, como os mais inovadores.

\section{Referências Bibliográficas}

ALVES, Luís Alberto Marques - O Porto no arranque do ensino industrial (1851-1910). Porto, Edições Afrontamento, 2003.

; SOUSA, Pedro Rodrigues de; MORAIS, Teresa Torrinhas; ARAÚJO, Francisco Miguel Veloso - Ensino Técnico (1756-1973). Lisboa, Ministério da Educação/Secretaria Geral, 2009.

ARAÚJO, Helena Costa - Pioneiras na educação - As professoras primárias na viragem do século 1870 -1933. Lisboa, Instituto de Inovação Educacional, 2000.

ARROYO, António José - Relatórios sobre o Ensino Elementar Industrial e Comercial. Lisboa, Imprensa Nacional, 1911.

CANDEIAS, António (direcção e coordenação) - Alfabetização e Escola em Portugal nos séculos XIX e XX - Os Censos e as Estatísticas. Lisboa, Fundação Calouste Gulbenkian, 2004.

${ }^{29}$ Projecto de lei sobre o Ensino Profissional Doméstico. Exposição à consideração da Câmara dos Deputados Legislatura 1, Sessão legislativa 1, Número da Acta 61, página 5-6). Grifo nosso. 
CANDEIAS, António (coord.) - Modernidade, Educação e Estatísticas na Ibero-América dos séculos XIX e XX. Lisboa, Educa, 2005.

CARDIM, José Eduardo de Vasconcelos Casqueiro - Do Ensino Industrial à Formação Profissional. As políticas públicas de qualificação em Portugal. Lisboa, Universidade Técnica de Lisboa, Volume 1, 2005.

CASTRO, Zília Osório de e ESTEVES, João (dir.) - Dicionário no Feminino (séculos XIX-XX). Lisboa, Livros Horizonte, 2005.

FERREIRA, A. Aurélio da Costa - Alguns documentos concernentes à minha passagem pelo Ministério do Fomento. Lisboa, 1914.

GRÁCIO, Sérgio - Ensinos Técnicos e Política em Portugal 1910-1990. Lisboa, Instituto Piaget, 1998.

GUINOTE, Paulo J.A. - A Educação no Feminino (1900-2000). Discursos, Números e Olhares. In. CASTRO, Zília Osório de [dir.] (2003) - "Falar de Mulheres - Da Igualdade à Paridade”, Lisboa, Livros Horizonte, 2003, pp. 153225

PATACHO, Emília - Relatório sobre assuntos de Higiene Especialmente aplicáveis ao Sexo Feminino para o Ensino Normal Primário".In. "Primeiro Congresso Pedagógico da Liga nacional de Instrução", Lisboa, Imprensa Nacional, 1909.

PINTO, Teresa - As Mulheres no Ensino Industrial Público: dos cursos industriais aos cursos de Lavores Femininos (1884-1910). In "Vértice”, II" série, Julho-Agosto de 2009.

PINTO, Maria Teresa Valente - A Formação Profissional das Mulheres no Ensino Industrial público (1884-1910). Realidades e Representações. Lisboa: Universidade Aberta, 2008 (Doutoramento em Estudos sobre as Mulheres). Reformas do Ensino em Portugal (1900-1910). Lisboa, Ministério da Educação, 1996, Tomo I - vol. IV.

SAMARA, Maria Alice - Operárias e Burguesas. As Mulheres no Tempo da República. Lisboa, A Esfera dos Livros, 2007.

SANTOS, Cândido dos - A Mulher e a Universidade do Porto. Porto, Universidade do Porto, 1991.

VIEIRA, Mário Lázaro Santos (2010)- A Escola Prática Comercial Raul Dória: Memória de um espaço de Ensino Comercial (1902-1964). Porto, FLUP (Dissertação de Mestrado em História e Educação). Porto, Agosto de 2010

Fontes:

Anuário Estatístico de Portugal - anos de 1905-1910, 1917, 1919, 1921, 1923, 1924, 1925, 1926, 1927, 1928, 1929 e 1930. Lisboa, Imprensa Nacional. 